\title{
25 Research Square \\ Hospital Utilization for Non-Traumatic Dental Conditions in Oregon from 2013 to 2015
}

Avery Brow ( $\square$ avery.brow@dentaquest.com )

DentaQuest Partnership for Oral Health Advancement https://orcid.org/0000-0002-4153-4952

Eric P. Tranby

DentaQuest Partnership for Oral Health Advancement

Sean G Boynes

DentaQuest Partnership for Oral Health Advancement

Research article

Keywords: Non-Traumatic Dental Conditions, Hospital Utilization, Coordinated Care Organizations (CCOs)

Posted Date: January 13th, 2020

DOI: https://doi.org/10.21203/rs.2.20734/v1

License: (1) This work is licensed under a Creative Commons Attribution 4.0 International License.

Read Full License 


\section{Abstract}

Introduction: Poor oral health remains a national concern impacting overall health and continues to burden an already overtaxed health care system. These issues are exacerbated by differing levels of coverage nationally, particularly in those states that lack any public oral health coverage. Those with significant and immediate need are forced to seek care from alternative settings and often are not equipped to provide dental treatment. Oregon operates a unique system called Coordinated Care Organizations (CCOs) designed to link providers from across disciplines and focus on prevention and chronic disease management.

Methods: Using claims data from the All-Payer, All-Claims (APAC) database, this paper evaluates claims from 2013 to 2015 for all patients presenting to an emergency department (ED) or as an inpatient for a non-traumatic dental condition (NTDC) in the state of Oregon.

Results: ED visits for NTDCs increased from 2013 to 2015 with 79\% of ED visits for a dental condition paid for by Medicaid, and those aged 20-34 had the highest visit rate across all 3 years. Black and American Indian or Alaskan Native patients had the highest ED utilization. Residents of rural counties were more likely to utilize the ED than urban county residents. $76 \%$ of patients visited the ED 1 time with a charge of $\$ 13,888,516$. Consistent with other findings, the increased visits are likely due to expanded Medicaid coverage. Increased usage by rural residents is also supported by other studies.

Conclusions: This paper continues to demonstrate the need for multi-level solutions that continue to decrease ED utilization across Oregon.

\section{Background}

Poor oral health continues to be a national issue impacting overall health while continuing to add cost to an already expensive United States (US) health care system. In fact, poor oral health increases the likelihood of negative outcomes and health status including: poor chronic condition management (1-5), poorer nutrition (6-7), lower quality of life (8), missed work and school days and enhances health disparities for many communities (9).

These issues can be heightened in many states given the uneven distribution or complete lack of public oral health benefits, poor oral health literacy, and lack of affordable dental care (10-11). Often, patients with immediate or significant needs are forced to seek care from alternative settings not positioned or equipped to provide that care, such as emergency departments (EDs) (12-13). Services provided in the ED are costly and generally focus on immediate relief of pain or infection, rather than offering comprehensive or preventive care (9). Nationwide, in 2010, it is estimated that these dental-related, medical visits cost an additional $\$ 1.7$ billion per year and $79 \%$ could be seen by a dental office, avoiding the need for an ED visit altogether (14). 
Addressing utilization of EDs and other inappropriate, alternative settings for the treatment of dental conditions remains a significant challenge for dental providers and insurers, particularly state Medicaid programs. Since 2014, the state of Oregon has utilized a unique system to offer health insurance coverage through regional coordinated care organization (CCO) networks, which link providers from across disciplines, including behavioral and oral health. CCOs focus on prevention and chronic disease management while limiting emergency department visits as a system-wide performance goal (15-17). Fifteen CCOs operate in the state and share responsibility for member health, measurement and quality improvement, transparency, and maintenance of costs. Additionally, in 2014, comprehensive dental coverage was re-established for adults (18).

This report evaluates both ED and inpatient hospital utilization for non-traumatic dental conditions (NTDCs) in Oregon from 2013 to 2015. The coordinated provision of care, and the purposeful inclusion of both dental and behavioral health within their model that are excluded from most other Medicaid programs makes the evaluation of ED and inpatient usage in Oregon valuable for both policy makers and state leaders, particularly as more states consider the inclusion, or expansion, of adult dental benefits within their own Medicaid programs.

\section{Methods}

This study was reviewed and approved by the Western Institutional Review Board and utilizes data available from the Oregon Health Authority's All-Payer, All-Claims Reporting (APAC) Database and contains three years of data from 2013 to 2015 (19). The dataset contains administrative claims data for all of Oregon's insured patients including medical, pharmacy, enrollment data, billed information, and provider information for those with commercial, Medicare, and Medicaid coverage (19). This data does not include any claims by uninsured individuals. Non-traumatic dental conditions were defined using the Association of State and Territorial Dental Directors (ASTDD) and the recently adopted Dental Quality Alliance (DQA) guidelines (20). Emergency department visits and inpatient admissions for dental conditions were analyzed separately.

Gender was dichotomously categorized as either male or female; age was divided into eight categories: $0-9,10-19,20-24,35-44,45-54,55-64,65-74$ and 75+. Race was defined as white, black, American Indian or Alaskan Native, Native Hawaiian or Pacific Islander, or another race; and ethnicity as Hispanic/Latino or not Hispanic/Latino. Fifty-five percent of the data on race and ethnicity is missing from the original data source. Rates per 10,000 population are calculated using census information (21). Payers were classified into one of 6 groups: commercial-employer provided, commercial self-insured, Medicaid, dual eligibles, Medicare-only, and other. Given that care provided in EDs is often only palliative, we also investigated repeat visits to the ED by patients for NTDCs. Data was evaluated for all counties in Oregon. All analyses were conducted in R and Stata 15.

\section{Results}


Both emergency department and inpatient visits for non-traumatic dental care more than doubled from 14,105 total visits in 2013 to 26,981 visits in 2015 for any insurance type (see Table 1). This is a direct result of Medicaid expansion enrollment, as similar patterns were observed in only Medicaid-enrolled patients with 9,798 total visits in 2013 and 21,758 visits in 2015. Inpatient and emergency department utilization peaked in 2014, both for those with all insurances and Medicaid-only; this finding is consistent with the literature demonstrating similar increases in 2014 with Medicaid expansion, and resulting declines in ED utilization beginning in 2015 (23).

Insert Table 1 about here.

ED visits for dental-related conditions were evening distributed across the state (Figure 1). Rates of ED visits among Medicaid enrollees are significantly higher in rural counties than non-rural counties $(t=2.18$, $\mathrm{p}<0.05)$. Baker, Crook, Douglas, Jefferson, Sherman, Union, and Wasco counties are all classified as rural and have the seven highest rates of ED visits for dental-related conditions in the state.

Insert Figure 1 about here.

Females access dental care through emergency and inpatient settings more frequently than males across all years (Figure 2). Individuals 20 to 34 represented the highest rate of visits to an emergency department for a dental-related condition for all years. Inpatient admissions remained steady in all age groups, except for those adults over 75, when inpatient admissions for dental-related conditions increased sharply. Patients identifying as black had the highest rate of ED utilization, followed by those identifying as either American Indian or Alaskan Native (Figure 3).

Insert Figures 2 and 3 about here.

Medicaid is more likely to pay for an ED or inpatient visit for a dental-related condition than ED or inpatient visits for other reasons. In 2015, 79\% of ED visits for any reason (Figure 4). Similarly, 39\% of inpatient admissions for dental conditions are paid for by Medicaid, compared to 33\% of ED visits for any reason (Figure 5).

The percentage of dental-related ED visits paid by Medicaid increased 12 percent from $67 \%$ in 2013 to $79 \%$ in 2015; a similar increase was seen for all-reason ED visits from $46 \%$ in 2014 to $56 \%$ in 2015 . At the same time, the share of costs paid by employer-provided commercial plans decreased both for all conditions, and for dental-related visits. Similar patterns were observed for dental-related inpatient admissions. Twenty-three percent of the inpatient admissions were paid for by Medicaid in 2013; this increased to $39 \%$ in 2015. This reduction is likely due to increased Medicaid expansion enrollments. Costs for all-reason inpatient admissions remained relatively steady across all insurance types, except for those with Medicare, and dual-eligibles.

Insert Figures 4 and 5 about here. 
Seventy-six percent of patients made only one visit to an emergency department (Figure 6). The charge for these visits was $\$ 13,888,516$. Thirteen percent made two or more visits to an ED for a dental-related condition within 365 days for a total charge of $\$ 1,367.909$. Among the $143 \%$ with more than one visit, the majority revisited an ED between 1 and 15 days of the initial, dental-related visit.

Insert Figure 6 about here.

\section{Discussion}

Oregon experienced higher utilization in both the ED and the inpatient admissions for NTDC at the outset of their Medicaid program. Previous analyses show that when adults gain coverage from public insurance programs there is an increase in utilization of all services, including emergency departments and that this trend continues for newly enrolled recipients for at least two years after enrollment (22-23). Additionally, inpatient admissions increased over the same time period as ED visits in our cohort. These findings correlate with previous studies looking at medically related increases in inpatient admissions after adult Medicaid expansion in Oregon and Connecticut (23-27). This finding, though similar, necessitates further exploration to conceptualize and understand the underlying interpersonal and social factors that are driving this trend.

Similarities with an analysis of Oregon ED utilization from 2010 were found (17). The authors of that analysis reported in 2015 that dental related issues represented the second most common discharge diagnosis in adults aged $20-39$. Additionally, $56 \%$ of oral health related visits resulted in prescriptions for both an opioid and an antibiotic; these visits averaged $\$ 402$ per visit (17). Direct agreement was found with this analysis that the utilization of the ED for non-traumatic dental care is a costly public health issue that does not result in chronic health and is more likely to affect susceptible residents of Oregon.

The findings of this analysis also correlate with other state-specific analysis that rural populations are more likely to utilize the ED for dental issues than for their non-rural counterparts. Increased utilization of the ED relates to the fact that rural areas are more likely to have dental care team shortages, rural adults and children are more likely to have untreated dental needs, and rural communities are associated with socioeconomic factors that enhance poor oral health and nutrition (28-30). A recent study conducted found rural children are more likely to have unmet dental needs, cite additional barriers in receipt of dental care, and have higher odds of an ED visit at least once in the past year (31). To make positive changes for rural children and adults, Oregon is implementing teledentistry programs with providers to increase access to services, particularly for those rural areas in the state. Implementation of these teledentistry programs offer promising advantages and care improvements for rural residents of the state (32).

\section{Conclusions}

It is likely that the increases seen in Oregon EDs and inpatient hospitalization utilization trends are the result of expanded Medicaid coverage and, at least partially, represents the shift in costs from the 
uninsured to Medicaid when they gained coverage under expansion, though this is not definitive as this data does not include the uninsured. The increase is likely also connected to the poor oral health of those patients who did not have access to dental care prior to expansion and may reflect inadequate existing provider networks to meet the pent-up demand for dental care, inadequate patient education about dental benefits, or poor literacy on the behalf of beneficiaries on where to seek appropriate care. Utilization of EDs is also higher due to geographic barriers faced by patients. A recent study shows that when patients experience lower spatial access to primary care services, they are more likely to then seek that care from an emergency department (33). This finding is also true for pediatric patients, a population that experiences universal coverage in Oregon (34). The need for multi-level solutions, such as referral programs between ED's and local dentists and programs that increase access to dental care for those without ready access, such as teledentistry and expanded practice dental hygienists to continue decreasing ED utilization for care that can be more effectively delivered in lower cost environments continues in Oregon. At-risk Oregonians appear to be the residents that will benefit most from these types of interventions and awareness campaigns.

\section{Abbreviations}

APAC: All-Payer, All-Claims database

ASTDD: Association of State and Territorial Dental Directors

$\mathrm{CCO}(\mathrm{s})$ : coordinated care organization(s)

DQA: Dental Quality Alliance

$\mathrm{ED}(\mathrm{s})$ : emergency department(s)

NTDCs: Non-Traumatic Dental Conditions

US: United States

\section{References}

1. Griffin SO, Baker LK, Griffin PM, Cleveland JL, Kohn W. Oral health needs among adults in the United States with chronic diseases. J Am Dent Assoc. 2009 Oct;140(10):1266-1274. Available from: https://doi.org/10.14219.jada.archive.2009.0050.

2. Singer RH, Stoutenberg M, Feaster DJ, Cai J, Hlaing WM, Metsch LR, et al. The association of periodontal disease and cardiovascular disease risk: results from the Hispanic Community Health Study/Study of Latinos. J Periodontol. 2018 Jul 20;89(7):840-857. Available from: https://doi.org/10.1002/JPER.17-0549.

3. Kholy KE, Genco RJ, Van Dyke TE. Oral infections and cardiovascular disease. Trends Endocrinol Metab. 2015 Jun;26(6):315-321. Available from: https://doi.org/10.1016/j.tem.2015.03.001. 
4. Hwang SL, Shim JL, Kang D, Choi J. Poor oral health predicts higher 10-year cardiovascular risk: a propensity score matching analysis. J. Cardiovasc Nurs. 2018 Sep/Oct;33(5):429-436. Available from: https://doi.org/10.1097/ JCN.000000000000497.

5. Liljestrand JM, Havulinna AS, Paju S, Mannisto S, Salomaa V, Pussinen P. Missing teeth predict incident cardiovascular events, diabetes, and death. J Dent Res. 2015 Aug;94(8):1055-1062. Available from: https://doi.org/10.1177/0022034515586352.

6. Palacios C, Joshi KJ. Nutrition and health: a two-way relationship. In Bales CW, Locher JL, Saltzman E. Handbook of Clinical Nutrition and Aging. New York, NY: Springer Health + Business; 2015. 91-98. Available from: https://doi.org/10.1007/978-1-4939-1929-1_5.

7. Hugo C, Cockburn N, Ford, P, March S, Isenring E. Poor nutritional status is associated with worse oral health and poorer quality of life in aged care residents. J Nurs Home Res Sci. 2016 Nov 4;2:118-122. Available from: https://dx.doi.org/10.14283/jnhrs.2016.18.

8. Chaffee BW, Rodrigues PH, Kramer PF, Vitolo MR, Feldens CA. Community Dent Oral Epidemiol. 2017 Jun;45(3):216-224. Available from: https://doi.org/10.1111/cdoe.12279.

9. Cohen LA, Bonito AJ, Eicheldinger C, Manski RJ, Macek MD, Edwards RR, et al. Comparison of patient visits to emergency departments, physicians offices, and dental offices for dental problems and injuries. J Public Health Dent. 2011 Winter;71(1):13-22. Available from: https://doi.org/10.1111/j.1752-7325.2010.00195.x

10. Henderson E, Dalawari P, Fitzgerald J, Hinyard L. Association of oral health literacy and dental visitation in an inner-city emergency department population. Int J Environ Res Public Health. 2018 Aug 15;15(8). Available from: https://doi.org/10.3390/ijerph15081748.

11. Willink A, Schoen C, Davis K. Dental care and Medicare beneficiaries: access gaps, cost burdens and policy options. Health Aff (Millwood). 2016 Dec 1;35(12):2241-2248. Available from: https://doi.org/10.1377/htlhaff.2016.0829.

12. Lee HH, Lewis CW, Saltzman B, Starks H. Visiting the emergency department for dental problems: trends in utilization, 2001 to 2008. Am J Public Health. 2012 Nov;102(11):e77-e83. Available from: https://doi.org/10.2105/AJPH.2012.300965.

13. Rampa S, Veeratrishul A, Raimondo M, Connolly C, Allareddy V, Nalliah P. Hospital-based emergency department visits with periapical abscess: updated estimates from 7 years. J Endod. 2019 Mar;45(3):250-256. Available from: https://doi.org/10.1016/j.joen.2018.12.004

14. Wall T, Nasseh K, Vujicic M. Majority of dental-related emergency visits lack urgency and can be diverted to dental offices. 2014. ADA Health Policy Institute: Chicago IL. Available from: https://www.ada.org/media/ADA/HPI/Files/HPIBrief_0814_1.pdf.

15. Kaiser Family Foundation. Medicaid in 2018. 2018. The Henry J. Kaiser Family Foundation: San Francisco CA.

16. Oregon Health Authority. Coordinated Care Organizations (CCO). n.d. State of Oregon: Salem OR. Available from: https://www.oregon.gov/oha/HSD/OHP/Pages/Coordinated-CareOrganizations.aspx. 
17. Sun BC, Chi DL, Schwarz E, Milgrom P, Yagapen A, Malveau S, et al. Emergency department visits for nontraumatic dental problems: a mixed-methods study. Am J Public Health. 2015 May;105(5):947955. https://doi.org/10.2105/AJPH.2014.302398.

18. Wallace NT, Carlson MJ, Mosen DM, Snyder JJ, Wright BJ. The individual and program impacts of eliminating Medicaid dental benefits on the Oregon Health Plan. Am J Public Health. 2011 Nov;101(11):2144-2150. Available from: https://doi.org/10.2105/AJPH.2010.300031.

19. Oregon Health Authority. Oregon All-Payer, All-Claims Database (APAC): An Overview. 2018. State of Oregon: Salem OR. Available from: https://www.oregon.gov/oha/HPA/ANALYTICS/APAC\%20Page\%20Docs/APAC-Overview.pdf.

20. Association of State and Territorial Dental Directors. Recommended Guidelines for Surveillance of Non-Traumatic Dental Care in Emergency Departments. 2017 Jul 6. Available from: https://www.astdd.org/docs/ed-dental-care-protocols-w-appendices-july-6-2017.pdf.

21. United States Census Bureau. Population and Housing Unit Estimates. n.d. Available from: https://www.census.gov/programs-surveys/popest/data/tables.html.

22. McMorrow S, Gates JA, Long SK, Kenney GM. Medicaid expansion increased coverage, improved affordability, and reduced psychological distress for low-income parents. Health Aff (Millwood). 2017 May;36(5):808-818. Available from: https://doi.org/10.1377/htlhaff.2016.1650.

23. Ladhania R, Haviland AM, Venkat A, Telang R, Pines JM. The effect of Medicaid expansion on the nature of new enrollees' emergency department use. Med Care Res Rev. 2019 May 27;73(3):213-224. Available from: https://doi.org/10.1177/1077558719848270.

24. Nikpay S, Buchmueller T, Hildebrand WO, Levy H. Early Medicaid expansion in Connecticut stemmed the growth in hospital uncompensated care. Health Aff (Millwood). 2015 Jul;34(7):1170-1179. Available from: https://doi.org/10.1377/hlthaff.2015.0107.

25. Anderson L, Cherala S, Traore E, Martin NR. Utilization of hospital emergency departments for nontraumatic dental care in New Hampshire, 2001-2008. J Community Health. 2011 Aug;36(4):513-516. Available from: https://doi.org/10.1007/s10900-010-9335-5.

26. Trikhacheva A, Page M, Gault H, Ochieng R, Barth BE, Cannon CM, et al. Dental-related emergency department visits and community dental care resources for emergency room patients. KS J Med. 2015 May;8(2):61-72. Available from: https://doi.org/10.17161/kjm.v8i2.11521.

27. McCormack LA, Jones SG, Coulter SL. Demographic factors influencing nonurgent emergency department utilization among a Medicaid population. Health Care Manag Sci. 2017 Sep;20(3):395402. Available from: https://doi.org/10.1007/s10729-016-9360-8.

28. Fos P, Hutchinson L. The state of rural oral health: a literature review. In Gamm L, Hutchinson $L$, Dabney B, Dorsey A. Rural Healthy People 2010: A Companion Document to Healthy People 2010, Vol. 2. 131-144. The Texas A\&M University: College Station TX. Available from: https://www.ruralhealthresearch.org/publications/311.

29. Braswell A, Johnson NN. Rural America's Oral Health Care Needs. 2013 Feb. Accessed from: https://www.ruralhealthweb.org/getattachment/Advocate/Policy- 
Documents/RuralAmericasOralHealthCareNeeds-(1).pdf.aspx?lang=en-US.

30. National Research Council. Improving access to oral health care for vulnerable and underserved populations. Washington DC: National Academies Press. 2011 Jul 13. Available from: http://iom.nationalacademies.org/Reports/2011/Improving-Access-to-Oral-Health-Care-forVulnerable-and-Underserved-Populations.aspx.

31. DeVoe JE, Krois L, Stenger R. Do children in rural areas still have different access to health care? Results from a statewide survey of Oregon's Food Stamp population. J Rural Health. 2009 Winter;25(1):1-7. Available from: https://doi.org/10.1111/j.1748-0361.2009.00192.x.

32. Daniel SJ, Kumar S. Teledentistry: a key component in access to care. J Evid Based Dent Pract. 2014 Jun;14(Suppl):201-208. Available from: https://doi.org/10.1016/j.jebdp.2014.02.008.

33. Fishman J, McLafferty S, Galanter W. Does spatial access to primary care affect emergency department utilization for nonemergent conditions? Health Serv Res. 2018 Feb;53(1):489-508. Available from: https://doi.org/10.1111/1475-6773.12617.

34. Gregory EF, Chamberlain JM, Teach SJ, Engstrom R, Mathison DJ. Geographic variation in the use of low-acuity pediatric emergency medical services. Pediatr Emerg Care. 2017 Feb;33(2):73-79. Available from: https://doi.org/10.1097/PEC.0000000000000581.

\section{Declarations}

\section{Ethics Approval:}

This work was reviewed and approved by the Western Institutional Review Board with Study Number 1178460 and the approval is granted with an expiration date of August 21, 2020.

Consent for Participation:

Not applicable.

\section{Availability of Data and Materials:}

The data that support the findings of this study are available from the Oregon Health Authority, Office of Health Analytics, but restrictions apply to the availability of these data, which were used under license for the current study, and so are not publicly available. Data are however available from the authors upon reasonable request and with permission of the Oregon Health Authority. 
The DentaQuest Partnership for Oral Health Advancement is a non-profit part of the larger DentaQuest family of companies, including Advantage Dental by DentaQuest. There are no other financial or funding sources.

\section{Funding:}

There were no funding sources for this study.

\section{Authors' Contributions:}

$A B$ contributed to the research design, drafting, writing and critical reviews of the manuscript. ET contributed to the research design, drafting, data analysis and critical review. SB contributed to the research design, writing, and critical review of the manuscript. All authors have read and approved the manuscript.

Acknowledgements:

The authors acknowledge Alister Suarez, consultant for DentaQuest, for his initial analysis, critical appraisal, and commentary on the manuscript and Justin Gonzalez, Director of Clinical Affairs at Advantage Dental, for his critical appraisal and review of the manuscript.

\section{Table}

Please see the supplementary files section to access Table 1.

\section{Figures}




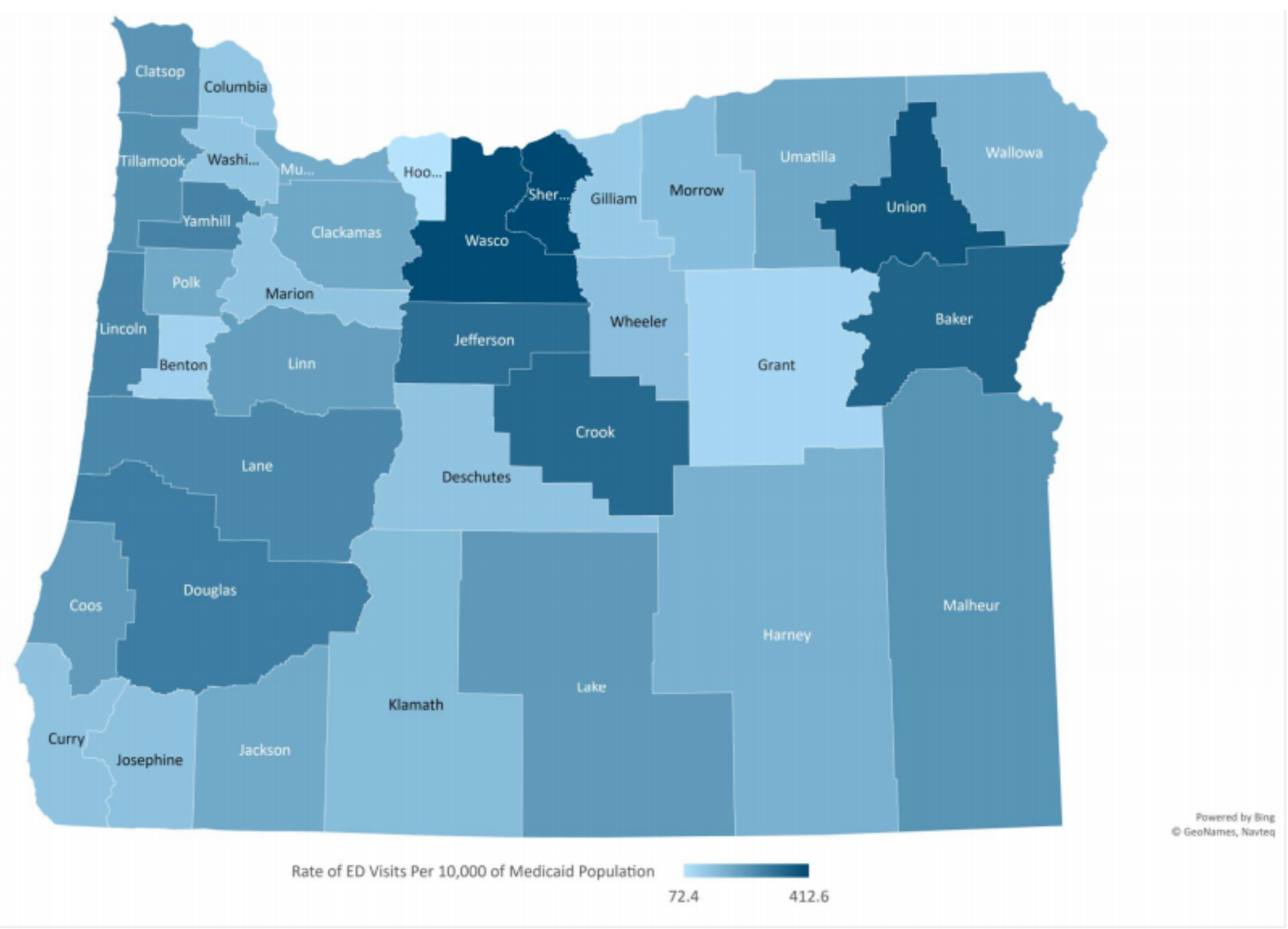

\section{Figure 1}

Rate of ED visits for non-traumatic dental conditions by Medicaid enrollees in Oregon counties in 2015 


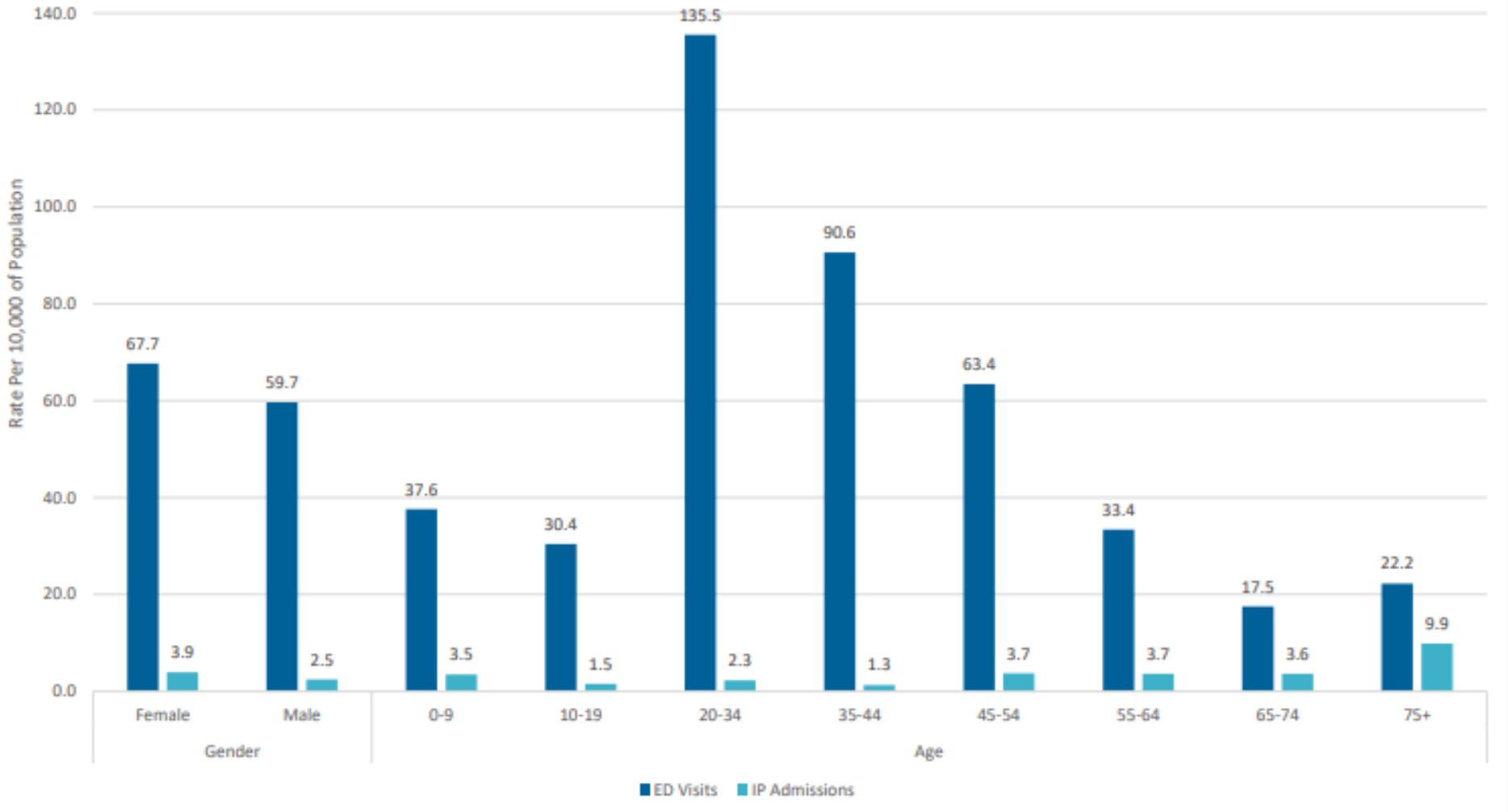

Figure 2

Rate of ED Visits and Inpatient Admissions for Dental Conditions, by Gender and Age, in Oregon 2015 


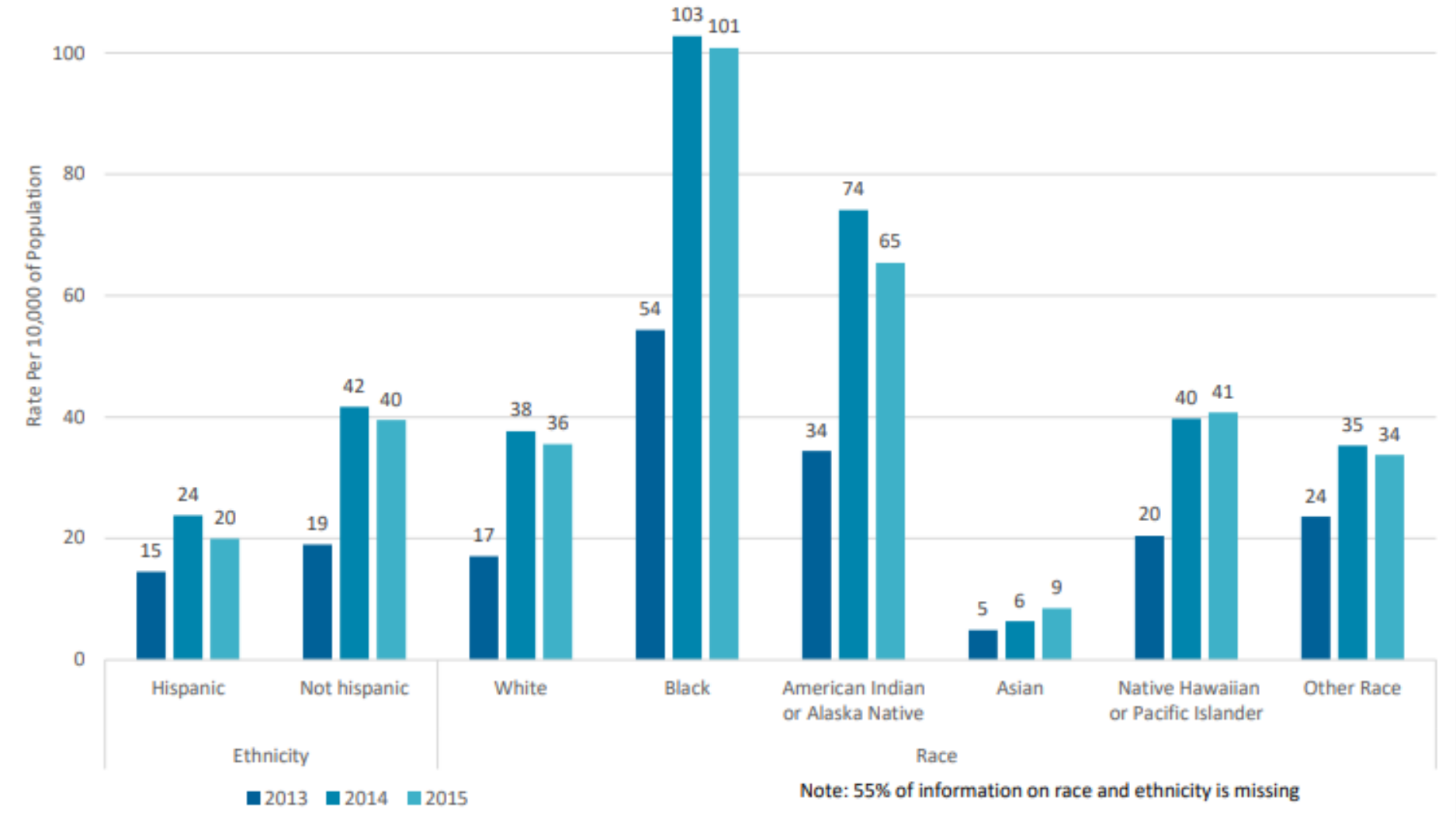

Figure 3

Rate of ED Visits for Dental Conditions, by Ethnicity and Race, in Oregon 2013-2015 


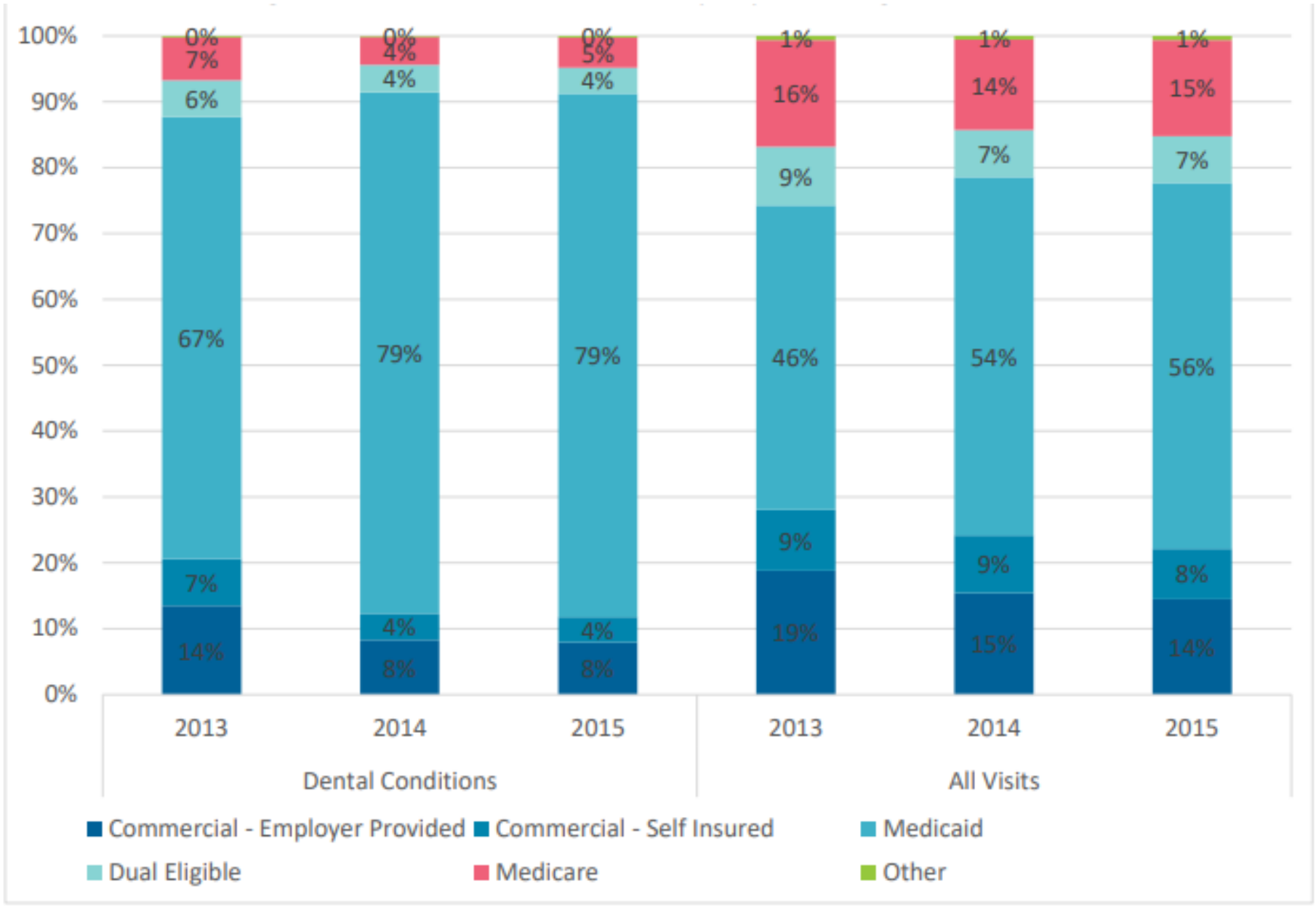

Figure 4

Distribution of ED Visits by Payer in Oregon 2013-2015 


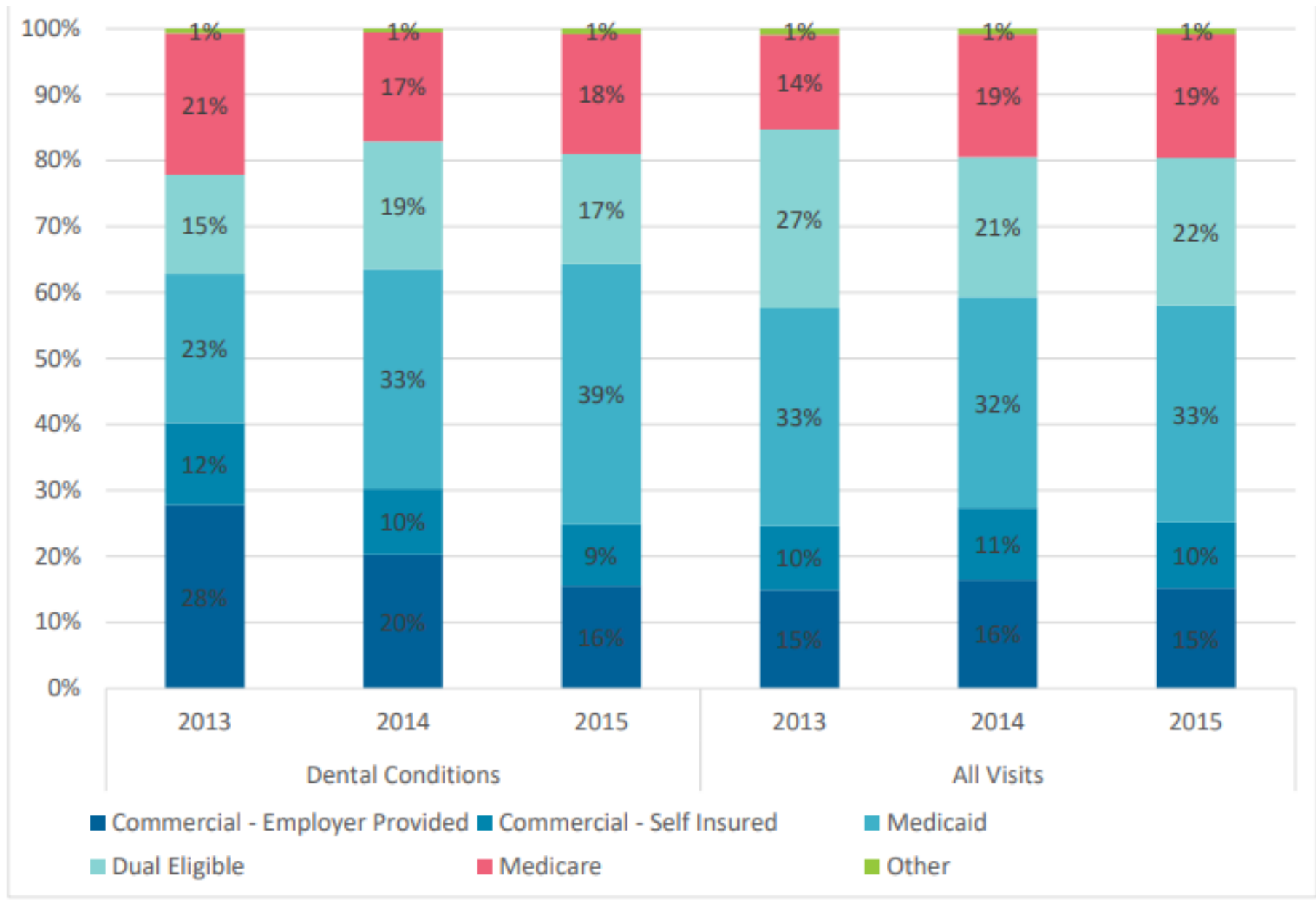

Figure 5

Distribution of Inpatient Admissions by Payer in Oregon 2013-2015

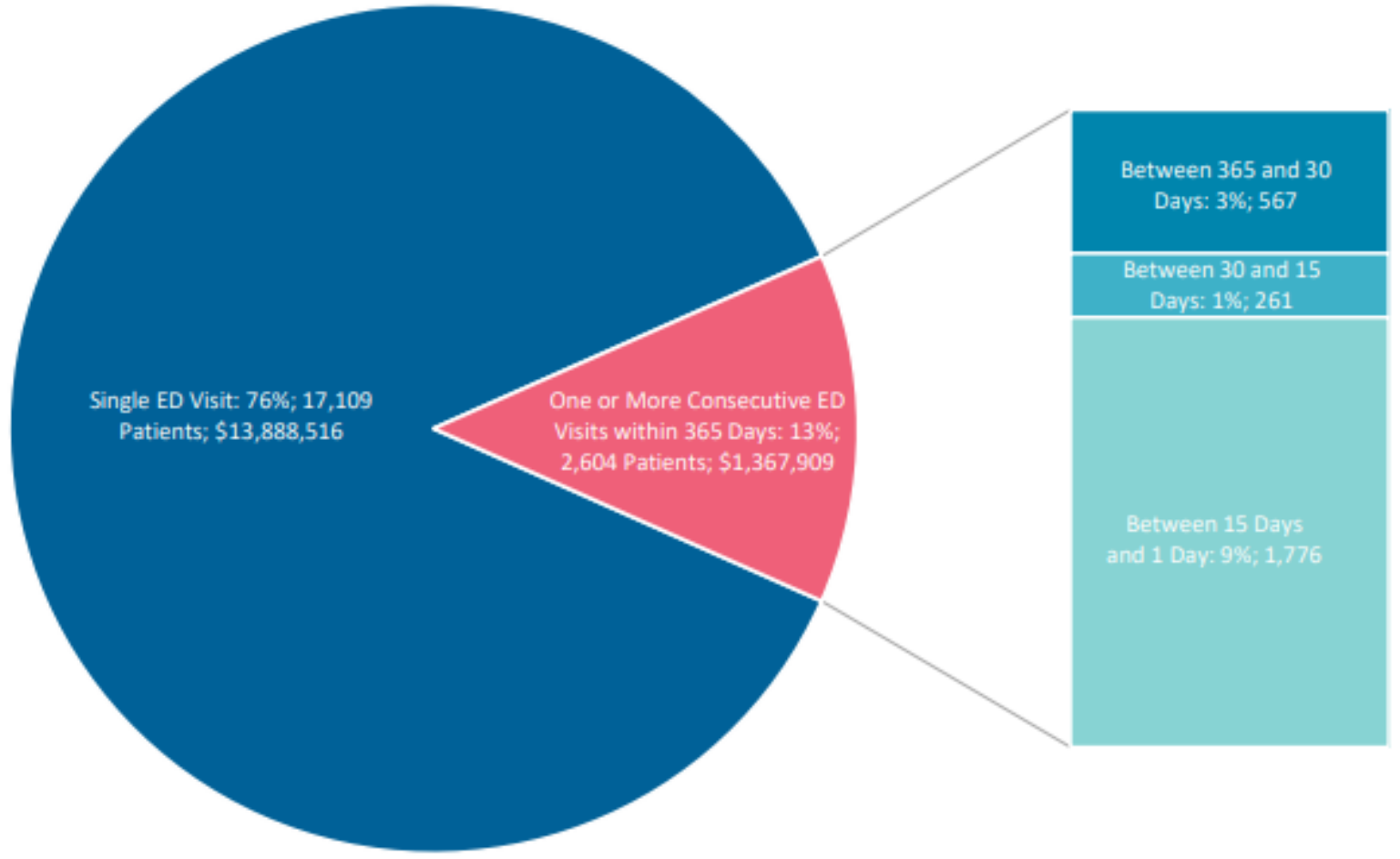

Page 15/16 
Figure 6

Distribution of ED Visits for Non-Traumatic Dental Conditions, by Number of Visits, in Oregon 2015

\section{Supplementary Files}

This is a list of supplementary files associated with this preprint. Click to download.

- Table1forSubmission.xIsx 